\title{
HSP27and Atherogenic Index of The Plasma -Heralding Cardiovascular Complications in Indian Diabetic Subjects
}

\author{
Prashant S. Ratnaparkhi' ${ }^{1,2}$, Namrata B. Kulkarni ${ }^{3}$, Meghana U. Ganu ${ }^{4}$, Sanjay G. Godbole ${ }^{5}$, Sudha S. Deo ${ }^{6}$ \\ ${ }^{1}$ M.Sc, Sir H.N. Medical Research Society, Sir H.N. Reliance Foundation Hospital and Research Centre, Raja Ram Mohan Roy Road, \\ Prarthana Samaj, Girgaum, Mumbai, 400004 India
}

${ }^{2}$ Department of Life Science and Biochemistry, St. Xavier's College, Mumbai 400001,India

${ }^{3}$ Ph.D. Sir H.N. Medical Research Society, Sir H.N. Reliance Foundation Hospital and Research Centre, Raja Ram Mohan Roy Road, Prarthana Samaj, Girgaum, Mumbai, 400004 India

${ }^{4}$ BAMS. Sir H.N. Medical Research Society, Sir H.N. Reliance Foundation Hospital and Research Centre, Raja Ram Mohan Roy Road, Prarthana Samaj, Girgaum, Mumbai, 400004, India

${ }^{5}$ M.D. Sir H.N. Medical Research Society, Sir H.N. Reliance Foundation Hospital and Research Centre, Raja Ram Mohan Roy Road, Prarthana Samaj, Girgaum, Mumbai, 400004 India

${ }^{6}$ Ph.D. Principal Investigator of the project. Sir H.N. Medical Research Society, Sir H.N. Reliance Foundation Hospital and Research Centre, Raja Ram Mohan Roy Road, Prarthana Samaj, Girgaum, Mumbai, 400004, India

Received: November 29, 2017; Accepted: December 11, 2017; Published: December 19, 2017

*Corresponding author: Dr. Sudha S. Deo, Ph.D. Principal Investigator of the project, Sir H.N. Medical Research Society, Sir H.N. Reliance Foundation Hospital and Research Centre, Raja Ram Mohan Roy Road, Prarthana Samaj, Girgaum, Mumbai, 400004 India;E-mail: sudha.deo@rfhospital.org

\section{Abstract}

Aim: To evaluate the importance of Heat shock protein 27 (HSP27) and Atherogenic Index of the Plasma (AIP) in diabetic subjects, as indicators of cardiovascular disease progression in diabetic subjects.

Materials and Methods: 144 subjects were recruited in 4 different groups as follows: Group A1- diabetic $>5$ years and hypertensive $(\mathrm{N}=55)$, Group A2 - diabetic < 2 years $(\mathrm{N}=28)$, Group B1 - hypertensive $(\mathrm{N}=31)$ and Group B2 - healthy controls $(\mathrm{N}=30)$. Anthropometric measurements were made and blood biochemistry profiles were established using standard protocols. AIP was calculated as Log (Triglycerides / HDL cholesterol), while HSP27 was measured using ELISA.

Results: HSP27 varied significantly across the groups (one-way ANOVA, ( $F(3)=4.95, p=0.003$ ). We saw significant increase in HSP27 levels between Groups A1 and B2, Groups A2 and B2, Groups A1 and B1, and Groups A2 and B1 ( $p=0.001,0.025,0.003$ and 0.043 respectively). AIP scores increased across the groups, although not significantly (one-way ANOVA, F $(3)=1.8, p=0.15$ ). The frequency of high risk AIP scores were more in Groups A1 and A2 as compared to the controls. HSP27 was negatively correlated with the AIP score, (Pearson's coefficient $=-0.173, p=0.039$ ). Two models of multivariate linear regression revealed that HSP27 and post prandial blood sugar (PPBS) were significant risk factors of AIP; F (5, 138) $=$ 3.069, $p=0.012, \mathrm{R}^{2}=0.10$. (Model $1, \mathrm{t}=-2.591, \mathrm{p}=0.011 ; 95 \% \mathrm{CI}=-0.269$ to -0.036 and model $2, \mathrm{t}=-2.332, p=0.021 ; 95 \% \mathrm{CI}=-0.256$ to -0.021 ).

Conclusion: Serum HSP27 and AIP increase in diabetic subjects with or without hypertension. The risk of cardiovascular complications can be monitored using HSP27.

Keywords: Atherogenesis, biomarkers, Heat-shock protein 27.

\section{Introduction}

Cardiovascular complications have become a major cause of death in the world, accounting for nearly $31 \%$ of deaths in 2015 according to WHO. Most important risk factors include obesity, lack of physical activity, smoking, hypertension and disarrayed lipid metabolism. Dyslipidaemia has been identified as a marker that can predict the risk of occurrence of type 2 diabetes mellitus and its associated complications [1]. Altered lipid parameters in diabetic conditions and derived lipid ratios can give useful insights towards atherogenic plaque formation and cardiovascular complications. Atherogenic index of the plasma (AIP) is defined as $\log _{10}$ (Triglyceride / HDL cholesterol),both parameters expressed as molar concentrations, and is considered 
to represent a unique relationship between the atherogenic and protective lipid content in the serum [2].

The role of lipids in accelerating cardiovascular complications is unequivocal. Long term diabetes mellitus results in a disarrayed metabolism of lipids, accumulation of triglycerides and low and very low density lipoproteins (LDL and VLDL). A corollary to this effect is increase in the levels of oxidized LDL cholesterol which is instrumental in accelerating the rate of plaque formation [3]. AIP has been used as a measurable entity for associating the risk of cardiovascular diseases in diabetic subjects along with the most commonly used Framingham Risk Score (FRS) [4- 6]. Another study in subjects with coronary artery disease in Asian population has identified that AIP could be used for discrimination between subjects affected with coronary artery disease [7]. The possibility of using AIP as a discriminatory score in the early and advanced diabetic subjects, for assessing the risk of cardiovascular disease will not only improve the management of diabetes in the subjects, but also prevent the ensuing risk of cardiovascular diseases [8].

Heat shock protein 27 (HSP27)belongs to the conserved class of small molecular weight chaperone proteins. They play a unique role in stabilization of the act in filaments, prevent the irreversible aggregation of unfolded proteins and confer resistance to cells during oxidative stress [9-11].HSP27 has been attributed to play important roles in diabetes mellitus and in atherogenic plaque formation as well[12,13]. One study has reported an increase in the levels of HSP27 in the serum of subjects with acute coronary syndrome as compared to the healthy controls in their study. They further report that the plaque region showed a characteristically lower concentration of this protein [14]. A seemingly contradictory observation has also been reported where in HSP27 levels were found to be higher in healthy individuals when compared to subjects suffering from coronary artery disease [15].

The purpose of our study was to identify whether the duration of diabetes (early stage and long term) had any influence on the levels of HSP27 in the serum of diabetic subjects. We also wanted to ascertain whether there was any correlation between AIP and the concentration of HSP27 in the serum of diabetic subjects. Such correlations could be useful indicators to evaluate the risk of atherogenic plaque formation and the progression of cardiovascular complications in type 2 diabetic subjects.

\section{Materials and Methods}

\section{Ethical issues}

The study was conducted upon the approval of the Scientific Advisory Committee of the Sir H.N. Medical Research Society, Sir H.N. Hospital and Research Centre, Mumbai, India. The procedures used in this study were carried according to the guidelines set by the ICMR for conducting research on human volunteers, which was in accordance to the Helsinki declaration, 2008.

\section{Study design}

\section{Selection and description of participants}

144 subjects, age $>40$ years, were selected for our study. After obtaining the informed consent from these subjects, their details were entered in the clinical proforma. The volunteers were divided into 4 groups; Group A1 = diabetic $>$ 5years with hypertension $(\mathrm{N}=55)$; Group $\mathrm{A} 2=$ diabetic $<2$ years, without hypertension ( $\mathrm{N}=28)$; Group B1 = hypertensive $(\mathrm{N}=31)$ and Group B2 = healthy controls $(\mathrm{N}=30)$. The norms for designation of diabetes and hypertension were followed according to American Diabetes Association (ADA) guidelines and the Joint National Committee (JNC) 7 guidelines respectively.

\section{Exclusion criteria}

Subjects below 40 years, and with major systemic illness, chronic inflammatory diseases and autoimmune diseases were excluded from the study.

\section{Procurement of Serum samples}

Venous blood was obtained using standard venepuncture procedures and serum thus obtained, was divided into set of 5 aliquots and stored at $-80^{\circ} \mathrm{C}$ till further assay.

Physical parameters like BMI, Waist: Hip ratio and Blood pressures (systolic and diastolic) were measured using standard protocols. Biochemical parameters of the volunteers were estimated using Konelab 20 i auto analyser.

\section{ELISA studies}

Ready to use ELISA kits were purchased and used for the estimation of Heat shock protein 27 (HSP27) (R\&D systems Minneapolis, US). All reagents and serum samples were brought to room temperature (freeze thaw cycles were avoided) and diluted as per kit instructions. Standards were prepared and ELISA assays were performed according to the instructions provided by the manufacturers. Serum samples were diluted (if required), to obtain absorbance values in agreement with the standard graph. Intra and inter assay controls were maintained in all ELISA experiments.

AIP was calculated as Log (Triglycerides / HDL cholesterol), both expressed in mmol/L, and compared with the reference groups for assessment of risks.

\section{Statistics}

Standard graphs were plotted using Curve Expert 1.4 software and concentrations in the unknown serum were determined using 4 th degree polynomial regression and taking the dilutions used into account. The results were analysed using IBM SPSS software version 21. Mean \pm SD were reported for all parameters in the study groups. Normality of the data was confirmed using Kolmogorov-Smirnov test. Distribution of the mean values across the groups was confirmed using ANOVA and the KruskalWallis test. Inter-group comparisons were performed using the Independent $t$ Test or Mann-Whitney $U$ test and significant deviations were identified with 95\% confidence interval limits. Correlations between the parameters in question and the groups in study was established using the Pearson's correlation coefficient or the Kendall rank correlation coefficient. Multiple linear regression was used to identify the parameters which possess greater prediction value. ROC curves were obtained to identify Area under the Curve $(\mathrm{AuC})$, and discriminating values were identified for FRS, HSP27 and AIP scores. 


\section{Results}

Table 1 depicts the results of anthropometric study, biochemical analyses and ELISA results for HSP27in our study groups. There was a significant increase in blood pressures (systolic and diastolic), blood sugar (fasting and post-prandial), Triglycerides; Total and LDL cholesterol as well as HbA1c among the diabetic groups $(p<0.05)$. Serum levels of HSP27 were found to be significantly elevated in the diabetic subjects when compared with the healthy controls, $(p=0.001$ and 0.025 respectively); and hypertensive group, ( $p=0.003$ and 0.043 respectively). Framingham Risk Score (FRS) was found to be significant across all the groups. We saw significant differences between all the groups $(p=0.000)$, except between diabetic and hypertensive groups. Although AIP values did not show any statistically significant difference across the groups, we saw an increase in the number of individuals having AIP value $>0.21$ in Group A1 and Group A2 as compared to the control group, as seen in Figure 1.

Table 1: Anthropometric measurements and biochemical analysis in study groups

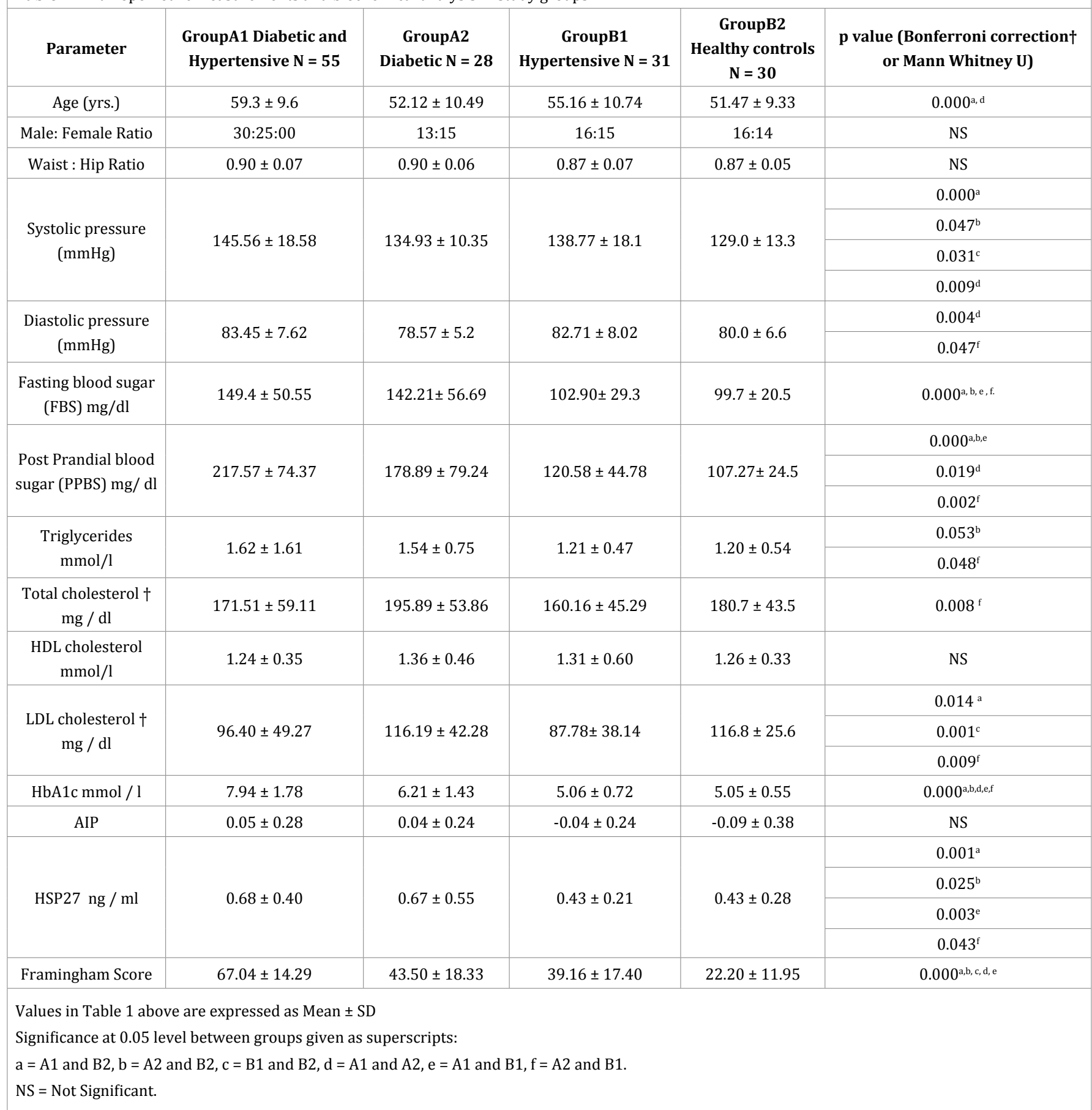




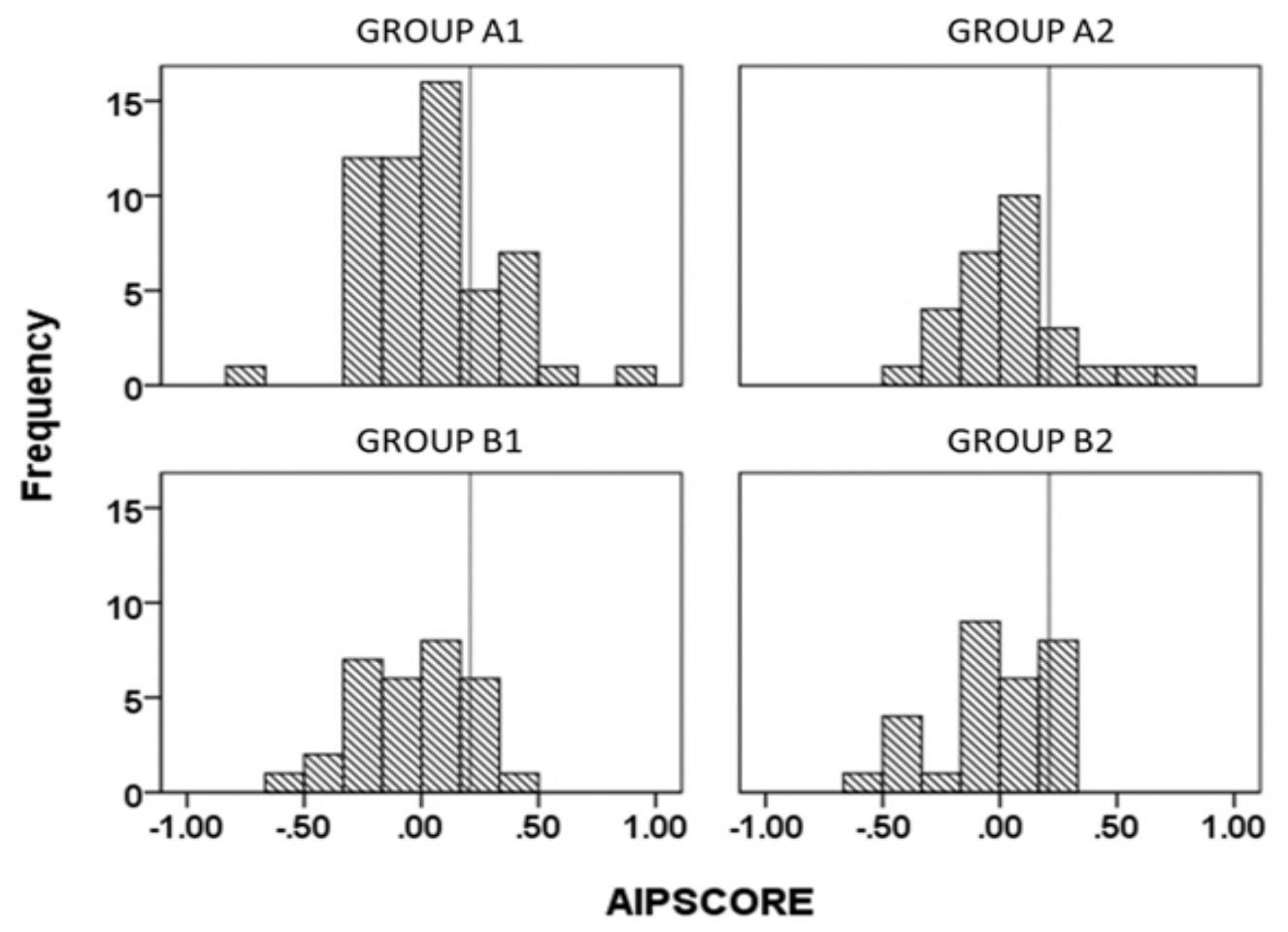

Figure 1: In Figure 1, the vertical line intersecting the X-axis is the AIP score of 0.21, which represents an increased risk of cardiovascular complications. The figure shows an increase in the number of subjects with AIP scores $>0.21$ in the diabetes and hypertensive groups (Groups A1 and A2) as compared to the control group (Group B2).

Table 2 depicts the correlation between various parameters and AIP. There was a positive Pearson's correlation of AIP with post prandial blood sugar $(\mathrm{r}=0.177, \mathrm{p}=0.033)$, and $\mathrm{HbA1c}(\mathrm{r}=$ $0.190, p=0.022$ ). AIP had a negative Pearson's correlation with HSP27 ( $r=-0.173, p=0.039)$, also seen in Figure 2.

Table 3 represents two multivariate regression models that reveal HSP27as a strong independent variable, which influences AIP $(\mathrm{t}=-2.332, \mathrm{p}=0.021,95 \% \mathrm{CI}$ from -0.256 to -0.021$)$ along with post prandial blood sugar $(\mathrm{t}=2.307, \mathrm{p}=0.023,95 \% \mathrm{CI}$ from 0.000 to 0.001 ), after adjusting for Age, BMI and Gender.

Figures $3 \mathrm{a}$ and $3 \mathrm{~b}$, are Receiver Operating Characteristics (ROC) curves which were obtained using a cut-off value of $156 \mathrm{mg}$ / dl (Mean $\pm 2 S D$ of the control group) for PPBS.

As seen in Figure 3a, a discriminatory score of FRS $=49.5$ was obtained with Area under the Curve $(\mathrm{A} \mathrm{u} \mathrm{C})=0.731, \mathrm{SE}=$ $0.043, \mathrm{p}=0.000 ; 95 \%$ confidence interval $(\mathrm{CI})$ of 0.646 and 0.815 whichcorresponded to the concentrations of HSP27 = $0.445 \mathrm{ng} / \mathrm{ml} ;(\mathrm{A} \mathrm{u} \mathrm{C})=0.606, \mathrm{SE}=0.047, \mathrm{p}=0.028$, with 95\% $\mathrm{CI}$ of 0.513 and 0.699 . AIP scores were non-significant as a test for discriminating the risk of cardiovascular complications in diabetic subjects.

When the diabetic groups (Groups A1 and A2) were combined together and compared with the non-diabetic groups (Groups B1 and B2), as seen in Figure 3b, a discriminatory score of FRS $=41.5$ was obtained with $(\mathrm{A} \mathrm{u} \mathrm{C})=0.849, \mathrm{SE}=0.033, \mathrm{p}=0.000 ; 95 \%$
CI of 0.786 and 0.911 . This corresponded to the concentration of $\mathrm{HSP} 27=0.435 \mathrm{ng} / \mathrm{ml}(\mathrm{A} \mathrm{u} \mathrm{C})=0.687, \mathrm{SE}=0.044, \mathrm{p}=0.000 ; 95 \%$ CI of 0.601 and 0.773 .

Table 2: Correlation of AIP with other parameters measured in study groups

\begin{tabular}{|c|c|c|}
\hline Parameter & $\begin{array}{c}\text { Pearson's } \\
\text { Correlation }\end{array}$ & $\begin{array}{c}\text { P value } \\
\text { 0.05\% level of } \\
\text { significance }\end{array}$ \\
\hline Age & 0.104 & 0.214 \\
\hline BMI & 0.135 & 0.108 \\
\hline Waist to Hip ratio & 0.162 & 0.054 \\
\hline Systolic BP & 0.05 & 0.55 \\
\hline Diastolic BP & 0.067 & 0.422 \\
\hline Fasting Blood Sugar & 0.21 & 0.011 \\
\hline Post Prandial Blood Sugar & 0.177 & 0.033 \\
\hline HbA1c & 0.190 & 0.022 \\
\hline HSP27 & -0.173 & 0.039 \\
\hline Framingham Score & 0.139 & 0.096 \\
\hline
\end{tabular}

As listed above in Table 2, we can see that AIP is positively correlated with serum blood sugar levels and HbA1c. HSP27 has a negative correlation with AIP. Age, BMI and blood pressure do not have a statistically significant correlation with AIP. 
Table 3: Multivariate Regression analysis for AIP.

\begin{tabular}{|c|c|c|c|c|c|c|c|c|}
\hline & \multirow[t]{2}{*}{ Model } & \multicolumn{2}{|c|}{ Unstandardized Coefficients } & \multirow{2}{*}{$\begin{array}{c}\text { Standardized } \\
\text { Coefficients } \\
\text { Beta }\end{array}$} & \multirow{2}{*}{$\mathbf{t}$} & \multirow{2}{*}{ Significance } & \multicolumn{2}{|c|}{$\begin{array}{c}95.0 \% \text { Confidence Interval } \\
\text { for B }\end{array}$} \\
\hline & & $\mathbf{B}$ & Std. Error & & & & $\begin{array}{l}\text { Lower } \\
\text { Bound }\end{array}$ & $\begin{array}{l}\text { Upper } \\
\text { Bound }\end{array}$ \\
\hline \multirow{3}{*}{1} & (Constant) & -.047 & .061 & & -.772 & .442 & -.167 & .073 \\
\hline & HSP27 & -.152 & .059 & -.214 & -2.591 & .011 & -.269 & -.036 \\
\hline & PPBS & .001 & .000 & .218 & 2.640 & .009 & .000 & .001 \\
\hline \multirow{5}{*}{2} & (Constant) & -.395 & .218 & & -1.816 & .072 & -.826 & .035 \\
\hline & HSP27 & -.139 & .059 & -.194 & -2.332 & .021 & -.256 & -.021 \\
\hline & PPBS & .001 & .000 & .192 & 2.307 & .023 & .000 & .001 \\
\hline & Age & .004 & .002 & .125 & 1.504 & .135 & -.001 & .008 \\
\hline & Gender & -.028 & .048 & -.048 & -.587 & .558 & -.123 & .067 \\
\hline
\end{tabular}

In Table 3, two models of regression are depicted. In both the models, HSP27 and Postprandial blood sugar levels are seen to be very strong predicting factors of AIP. Age, BMI and Gender are not significant in predicting AIP.

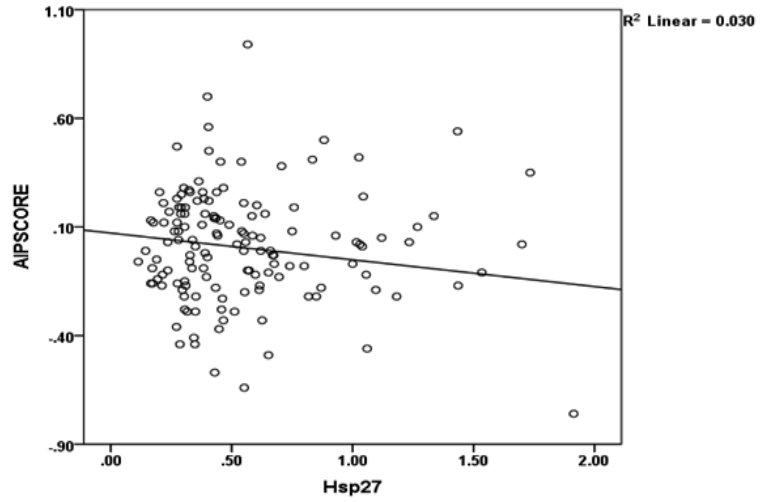

Figure 2: Scatter plot depicting the relation between AIP scores and HSP27

In Figure 2, we can see that HSP27 is negatively correlated with AIP score. The coefficient of determination R2 $=0.03$. HSP27 can account for $3 \%$ of the variability seen in the AIP score. HSP27 exhibits a linear relationship with AIP score.

\section{Discussions}

Diabetic subjects have been reported to have a greater risk of myocardial infarction due to altered lipid profiles [16]. Our study focussed on the impact of short and long-term diabetes on AIP score and HSP27 in our subjects. Our results validate that FRS is a good indicator of the risk of cardiovascular diseases in diabetic subjects. This has been in consonance to one such study published in north Indian population [17]. In our study, we found increasing number of subjects with diabetes having AIP scores $>0.21$ as compared to the controls. We did not however find statistical significance in the distribution of AIP scores in our subjects. This is contrary to many reports published in diabetic subjects $[18,19,20]$. AIP score has been reported to reduce in type 2 diabetes subjects due to reduction of serum triglycerides, and due to treatment of diabetic subjects using pioglitazone, Tracking

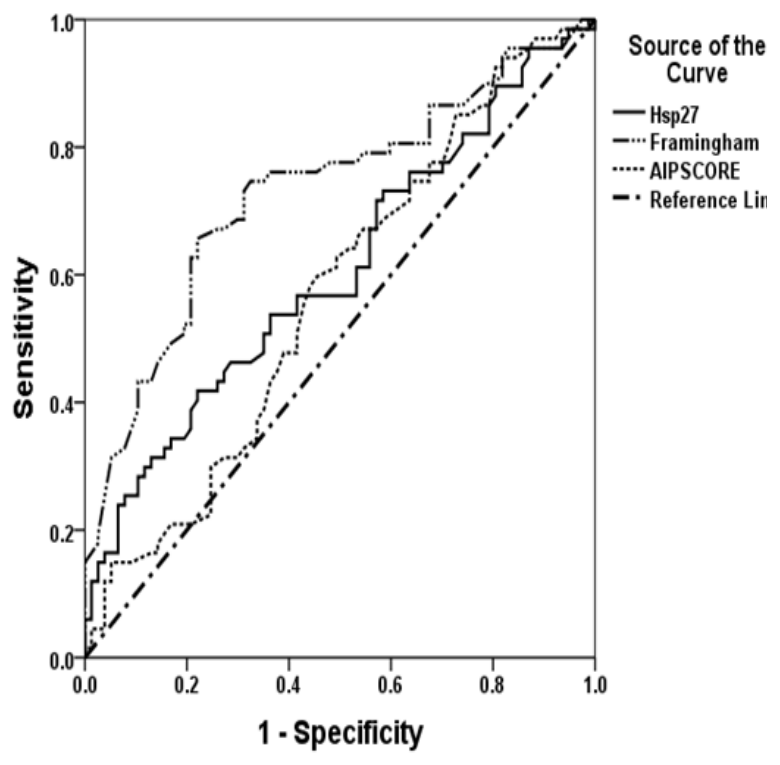

Figure 3a: Receiver Operating Characteristics (ROC) curve for HSP27, FRS and AIP score for study groups

Figure 3a represents ROC curves of FRS, HSP27 and AIP for the study population. Post prandial blood sugar $=156 \mathrm{mg} / \mathrm{dl}$ (Mean $\pm 2 \mathrm{SD}$ of the control group) was used as a cut off value. The A U C value for FRS was 0.731 ( $p=0.000,95 \%$ CI from 0.646 to 0.815 ) and for HSP27 was 0.606 ( $p=0.028,95 \% \mathrm{CI}$ from 0.513 to 0.699 ) respectively. The discriminatory values obtained from these ROC curves were 49.5 for FRS and $0.445 \mathrm{ng} /$ $\mathrm{ml}$ for HSP27.

the increase and decrease in the AIP score can be of clinical significance for the assessment of cardiovascular complications in diabetic subjects $[21,22]$.

We also found that HSP27 is indeed significantly increased in the subjects with diabetes, with or without hypertension (Groups 


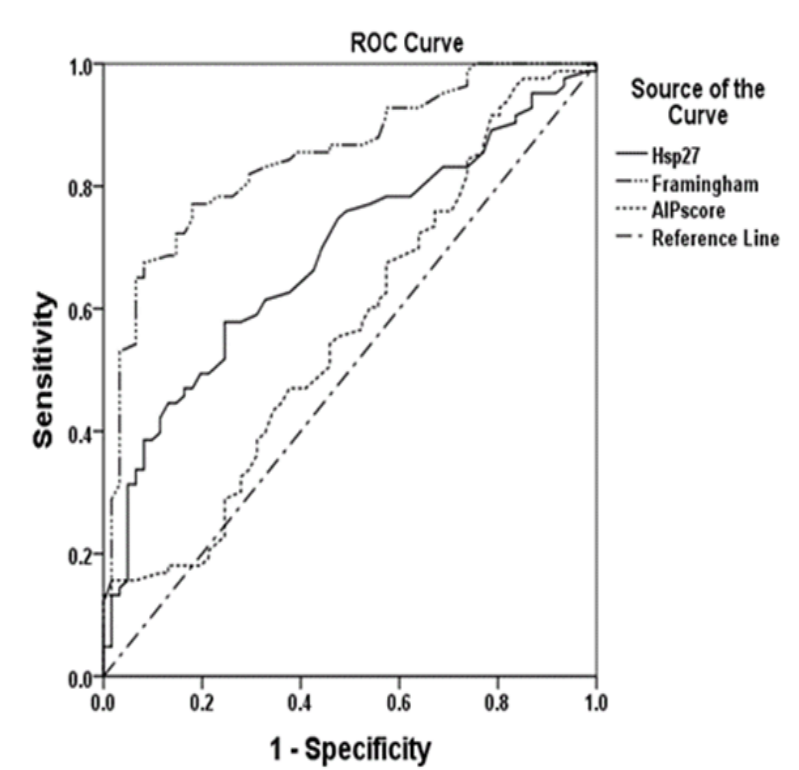

Figure 3b: Receiver Operating Characteristics (ROC) curve for HSP27, FRS and AIP score for diabetic versus non-diabetic populations Figure $3 \mathrm{~b}$ represents the ROC curves of FRS, HSP27 and AIP for the population differentiated as diabetic (Groups A1 and A2) and non-diabetic (Groups B1 and B2). The post prandial blood sugar $=156 \mathrm{mg} / \mathrm{dl}($ Mean \pm 2 SD of the control group) was used as a cut off value. The A U C value for FRS is 0.849 ( $p=0.000,95 \% \mathrm{CI}$ from 0.786 to 0.911$)$ and for HSP27 is 0.687 ( $p=0.000,95 \% \mathrm{CI}$ from 0.601 to 0.773 ) respectively. The discriminatory values obtained from these ROC curves are 41.5 for Framingham Score and $0.435 \mathrm{ng} / \mathrm{ml}$ for HSP27.

A1 and A2), when compared with the controls (Group B2). This has also been reported in one such study [23]. Our results demonstrate that HSP27 has a negative correlation with AIP score. This could be probably because HSP27 has a protective function, in chaperoning various enzymes needed for metabolism, or in reducing the ROS load generated during the pathophysiology of diabetes[11]. The ROC curve demonstrates that FRS has the highest Area under the curve (A U C), which was 70.1\%, followed by HSP27, which was $60.6 \%$. AIP score exhibited an A U C which was non-significant. The cut-off value of $0.435 \mathrm{ng} / \mathrm{ml}$ for HSP27, which we obtained using the ROC curve, can be validated using a larger study population, and can be considered in regular clinical evaluation.

Thus we conclude that HSP27 is surely a very important molecule to monitor during early stages of diabetes (i.e. up to 2 years), as well as in long term diabetes, (i.e. $>5$ years), as it positively correlates with Atherogenesis and cardiovascular complications. Negative correlation of AIP with HSP27 emphasizes the important role of HSP27 in preventing plaque formation and reducing the risk of cardiovascular complications. It has been reported that areas of myocardial infarcts show a marked reduction in the concentration of HSP27 in comparison to the nearby healthy tissue areas [24]. An increase in the circulating levels of HSP27 could probably be associated with maintaining homeostasis and reversing the damage caused by diabetes. But as the disease progresses, the levels of HSP27 in the cardiac tissues reduce to values which can cause apoptosis of cells [14].

\section{Conclusion}

The limitation of our study is the modest number of subjects recruited. This can be alleviated by corroborating this study with a larger population, especially in diabetic subjects in the age group of $30-40$ years, and in subjects identified with type 2 diabetes less than 2 years.

Considering the fact that various systemic and metabolic diseases like diabetes eventually manifest into heart ailments, early diagnosis of cardiovascular risks is the need of the hour. Our cross-sectional study attempts to add value to the existing information in the field of early diagnosis of cardiovascular complications in diabetic subjects. We conclude by emphasizing that HSP27 and AIP score has a great potential to be included in regular clinical diagnosis and monitoring circulating levels of HSP27 and AIP scores in early and long-term diabetic subjects could improve the detection of cardiovascular risk in diabetic subjects, thus reducing the morbidity and mortality found in these subjects.

\section{Acknowledgement}

Authors would like to express special thanks to the Director and the Management of Sir H. N. Reliance Foundation Hospital and Research Centre for providing us with the necessary funds to carry out this project. We are also grateful to ethics review committee and scientific advisory committee for approving this project. We would like to thank other laboratory staff for their direct and indirect help. Last but not least we would like to thank our participants for their precious time and blood samples.

\section{Grant Support}

The research has been funded by the Sir H.N. Reliance Foundation Hospital and Research Centre.

\section{Ethical Approval}

The study was conducted upon the approval of the Scientific Advisory Committee of the Sir H.N. Medical research Society, Sir H.N. Hospital and Research Centre, Mumbai, India. The procedures used in this study were carried according to the guidelines set by the ICMR for conducting research on human volunteers, which was in accordance to the Helsinki declaration, 2008.

\section{References}

1. American Diabetes Association. Standards of Medical Care in Diabetes. 2017.

2. Dobiasova M. VnitrLek. 01 Jan 2006, 52(1):64-71

3. Levitan I, Volkov S, Subbaiah P.V. Oxidized LDL: Diversity, Patterns of Recognition, and Pathophysiology. Antioxidants \& Redox Signaling. 2010;13(1):39-75. doi:10.1089/ars.2009.2733.

4. Zhu XW, Deng FY, Lei SF. Meta-analysis of Atherogenic Index of Plasma and other lipid parameters in relation to risk of type 2 diabetes mellitus. Prim Care Diabetes. 2015; 9(1):60-67. doi:10.1016/j. pcd.2014.03.007

5. Hubert HB, Feinleib M, McNamara PM, Castelli WP. Obesity as an independent risk factor for cardiovascular disease: A 26 year follow- 
up of participants in the Framingham Heart Study. Circulation. 1983;67(5):968-977.

6. Ahmad FS, Ning H, Rich JD, Yancy CW, Lloyd-Jones DM and Wilkins JT. Hypertension, Obesity, Diabetes and Heart Failure-Free Survival: The Cardiovascular Lifetime Risk Pooling Project. JACC Heart Fail. 2016;4(12): 911-919. doi:10.1016/j.jchf.2016.08.001

7. Gaojun C, Ganwei S, Sheliang X, Wei L. The atherogenic index of plasma is a strong and independent predictor for coronary artery disease in the Chinese Han population. Medicine. 2017;96(37):8058-8063. doi:10.1097/MD.0000000000008058.

8. Pithova P, Stechova K, Pitha J, Lanska V, Kvapil M. Determinants of preclinical atherosclerosis are different in type 1 and type 2 diabetic women. Physiol Res. 2016;65(2):219-28.

9. Lavoie JN, Gingras-Breton G, Tanguay RM, Landry J. Induction of Chinese hamster HSP27 gene expression in mouse cells confers resistance to heat shock. HSP27 stabilization of microfilament organization. J Biol Chem. 1993;268(5):3420-3429

10. Jakob U, Gaestel M, Engel K, Buchner J. Heat shock proteins are molecular chaperones. J Biol Chem. 1993;268:1517-1520

11. Rogalla T, Ehrnsperger M, Preville X, et al. Regulation of Hsp27 oligomerization, and protective activity against oxidative stress / Tumor necrosis factor alpha by phosphorylation. J Biol Chem. 1999; 274(27):18947-18956

12. Singh K, Agrawal NK, Gupta SK, Mohan G, Chaturvedi S and Singh K.: Decreased expression of heat shock proteins may lead to compromised wound healing in type 2 diabetes mellitus patients. J Diabetes Complications. 2015;29(4):578-88. doi:10.1016/j. jdiacomp.2015.01.007

13. Raizman JE, Chen YX, Seibert T, Hibbert B, Cuerrier CM, Salari S, et al. Heat shock protein-27 attenuates foam cell formation and atherogenesis by down-regulating scavenger receptor-A expression via NF- $\mathrm{KB}$ signaling. Biochim Biophys Acta. 2013;1831 (12):17211728. doi:10.1016/j.bbalip.2013.07.015.

14. Park HK, Park EC, Bae SW, Park MY, Kim SW, Yoo HS, et al. Expression of heat shock protein 27 in human atherosclerotic plaques and increased plasma level of heat shock protein 27 in patients with acute coronary syndrome. Circulation. 2006;114:886-893. doi:10.1161/ CIRCULATIONAHA.105.541219

15. Seibert TA, Hibbert B, Chen YX, Rayner K, Simard T, Hu T, et al. Serum heat shock protein 27 levels represent a potential therapeutic target for atherosclerosis: observations from a human cohort and treatment of female mice. J Am CollCardiol. 2013; 62(16):1446-1454. doi:10.1016/j.jacc.2013.05.041
16. Kvan E, Pettersen KI, Sandvik L, Reikval A. High mortality in diabetic patient with acute myocardial infarction: Cardiovascularcomorbidities contribute most to the high risk. Int J Cardiol. 2007;121(2):184-188. doi:10.1016/j.ijcard.2006.11.003

17. Bansal D., NayakalluRamya SR., Gudala K., Vyamasuni R., Bhansali A. Agreement between Framingham Risk Score and United Kingdom Prospective Diabetes Study Risk Engine in identifying high coronary heart disease risk in North Indian population. Diabetes and Metabolism Journal. 2015;39(4):321-327. doi:10.4093/dmj.2015.39.4.321

18. Gaziano JM, Hennekens CH, O’Donnell CJ, Breslow JL, Buring JE. Fasting triglycerides, high-density lipoprotein and the risk of myocardial infarction. Circulation. 1997;96:2520-2525. doi:10.1161/01. CIR.96.8.2520

19. Dobiasova M, Frohlich J. The plasma parameter log (TG/HDL-C) as an atherogenic index: correlation with lipoprotein particle size and esterification rate in apoB-lipoprotein-depleted plasma (FERHDL). Clin Biochem. 2001;34(7):583-588.

20. Nwagha UI, Ikekpeazu EJ, Ejezie FE, Neboh EE, Maduka IC. Atherogenic index of plasma as useful predictor of cardiovascular risk among postmenopausal women in Enugu, Nigeria. Afr Health Sci. 2010;10(3):248-252.

21. Mirmiran P, Bahadoran Z, Golzarand M, Rajab A, Azizi F. Ardeh (Sesamumindicum) could improve serum triglycerides and atherogenic lipid parameters in type 2 diabetic subjects: a randomized clinical trial. Arch Iran Med. 2013;16(11):651-656. doi:0131611/ AIM.008.

22. Meng H, Tan DJ, Glazer BN. Pioglitazone Reduces Atherogenic Index of Plasma in Patients with Type 2 Diabetes. ClinChem. 2004;50(7):1184-1188. doi:10.1373/clinchem.2004.031757

23. Giannessi D, Colotti C, Maltinti M, Del Ry S, Prontera C, Turchi S, et al. Circulating heat shock proteins and inflammatory markers in patients with idiopathic left ventricular dysfunction: their relationships with myocardial and micro vascular impairment. Cell Stress Chaperones. 2007;12(3):265274. doi:10.1379/CSC-272.1

24. Wick G, Jakic B, Buszko M, Wick M., Grundtman C. The role of heat shock proteins in atherosclerosis. Nature Reviews Cardiology. 2014;11:516-529. doi:10.1038/nrcardio.2014.91 